\title{
Chapter 1 \\ Public Health Ethics: Global Cases, Practice, and Context
}

\author{
Leonard W. Ortmann, Drue H. Barrett, Carla Saenz, Ruth Gaare Bernheim, \\ Angus Dawson, Jo A. Valentine, and Andreas Reis
}

\subsection{Introduction}

Introducing public health ethics poses two special challenges. First, it is a relatively new field that combines public health and practical ethics. Its unfamiliarity requires considerable explanation, yet its scope and emergent qualities make delineation difficult. Moreover, while the early development of public health ethics occurred in a Western context, its reach, like public health itself, has become global. A second challenge, then, is to articulate an approach specific enough to provide clear

The opinions, findings, and conclusions of the authors do not necessarily reflect the official position, views, or policies of the editors, the editors' host institutions, or the authors' host institutions.

L.W. Ortmann, $\mathrm{PhD}(\bowtie) \bullet$ D.H. Barrett, $\mathrm{PhD}$

Office of Scientific Integrity, Office of the Associate Director for Science,

Office of the Director, Centers for Disease Control and Prevention, Atlanta, GA, USA

e-mail: lortmann@cdc.gov

C. Saenz, PhD

Regional Program on Bioethics, Office of Knowledge Management, Bioethics, and Research, Pan American Health Organization, Washington, DC, USA

R.G. Bernheim, JD, MPH

Department of Public Health Sciences, University of Virginia, Charlottesville, VA, USA

A. Dawson, $\mathrm{PhD}$

Center for Values, Ethics and the Law in Medicine, Sydney School of Public Health,

The University of Sydney, Sydney, Australia

J.A. Valentine, MSW

Division of STD Prevention, National Center for HIV/AIDS, Viral Hepatitis, STD, and TB

Prevention, Centers for Disease Control and Prevention, Atlanta, GA, USA

A. Reis, MD, MSc

Global Health Ethics, Department of Information, Evidence and Research,

World Health Organization, Geneva, Switzerland 
guidance yet sufficiently flexible and encompassing to adapt to global contexts. Broadly speaking, public health ethics helps guide practical decisions affecting population or community health based on scientific evidence and in accordance with accepted values and standards of right and wrong. In these ways, public health ethics builds on its parent disciplines of public health and ethics. This dual inheritance plays out in the definition the U.S. Centers for Disease Control and Prevention (CDC) offers of public health ethics: "A systematic process to clarify, prioritize, and justify possible courses of public health action based on ethical principles, values and beliefs of stakeholders, and scientific and other information" (CDC 2011). Public health ethics shares with other fields of practical and professional ethics both the general theories of ethics and a common store of ethical principles, values, and beliefs. It differs from these other fields largely in the nature of challenges that public health officials typically encounter and in the ethical frameworks it employs to address these challenges. Frameworks provide methodical approaches or procedures that tailor general ethical theories, principles, values, and beliefs to the specific ethical challenges that arise in a particular field. Although no framework is definitive, many are useful, and some are especially effective in particular contexts. This chapter will conclude by setting forth a straightforward, stepwise ethics framework that provides a tool for analyzing the cases in this volume and, more importantly, one that public health practitioners have found useful in a range of contexts. For a public health practitioner, knowing how to employ an ethics framework to address a range of ethical challenges in public health - a know-how that depends on practice-is the ultimate take-home message.

We learn new things more readily when we can relate them to familiar things, and we understand complex things by breaking them into their components. Accordingly, throughout this introductory chapter, we will relate public health ethics to more familiar concepts and better-known related fields, while the immediately following section will explore the components of public health ethics that derive from its parent disciplines of public health and ethics. After describing public health's core activities, goals, and values, we will explain why ethical concepts like the right to health, social justice, and health equity directly follow as central concerns of public health. After defining ethics broadly in everyday terms, we will examine the complementary roles facts and values play in public health. This examination is important because the respective bases of the two parent disciplines differ considerably; public health science rests on the logic of scientific discovery, whereas ethics rests on the logic of right action and good decision making. We will then contrast the more familiar, everyday understanding of morality with the formal discipline of ethics as a prelude to considering three well-known ethical theories relevant to public health. Because both laws and ethical rules establish parameters for public health practice, their similarity and difference need to be clarified. This extended account, first of parent disciplines, then of kindred concepts, and finally of family resemblances between the related fields of clinical ethics, bioethics, and research ethics, will culminate in an effort to characterize what is distinctive about public health ethics. 


\subsection{Public Health}

There are many definitions of public health. They often begin as descriptions of current practice but once established become prescriptions for subsequent practice. It is important, then, to consider definitions, because they shape not only public health practice, but also how we conceive of public health ethics (Dawson and Verweij 2007). The same logic applies to how we think about the individual concepts of health and the public. Defining health as the absence of disease or symptoms, for example, more readily fits allopathic medicine, which focuses on negating symptoms to treat disease. But it hardly fits public health's emphasis on preventive measures that address root causes rather than symptoms. Nor does it cover public health's promotion of health and well-being across a range of interventions. In this regard, the World Health Organization (WHO) offers a definition of health more suitable to public health: "A state of complete physical, mental, and social wellbeing and not merely the absence of disease or infirmity" (WHO 2006). But even this more holistic definition does not sufficiently clarify the meaning of "public" in public health. Dawson and Verweij (2007) identify two primary meanings of "public" in public health, each of which they break down into three senses. Public can mean population-wide and refer to (1) the epidemiologically measured health of a population or group, (2) the distribution of health in a population, or (3) the underlying social and environmental conditions impacting everyone's health. Public also can mean collectively accomplished and requiring (1) the concerted actions of many people and institutions whether governmental or nongovernmental; (2) the cooperation or involvement of the public, or (3) the public's joint participation to realize the health improvement.

In a practical field like public health, definition often takes the form of enumerating key activities, such as surveillance, sanitation, maintaining food and workplace safety, disease prevention and control, and promoting healthy behavior. The identification of the ten essential services of public health illustrates this enumerative approach (Fig. 1.1) (Public Health Functions Steering Committee 1994). These services fall under three overarching functions of assessment, policy development, and assurance that constitute an integrated cyclic process. The delivery of these services in local, regional, or national public health agencies accordingly defines public health practice. In this schema, research is a distinct practical service but also integral to all public health activities, providing insights and innovative solutions at every point. Public health ethics addresses the entire spectrum of ethical issues that arise in any area of public health practice but especially in those areas where no specific guidelines govern practice.

Such lists have the advantage of concretely specifying current activities but lack criteria that definitions normally provide for including or excluding additional activities as a field develops. In 1920, Charles Edward A. Winslow, an influential public health theorist and leader, pioneered a definition of public health that still informs many European and international public health institutions, including WHO (Marks et al. 2011). 


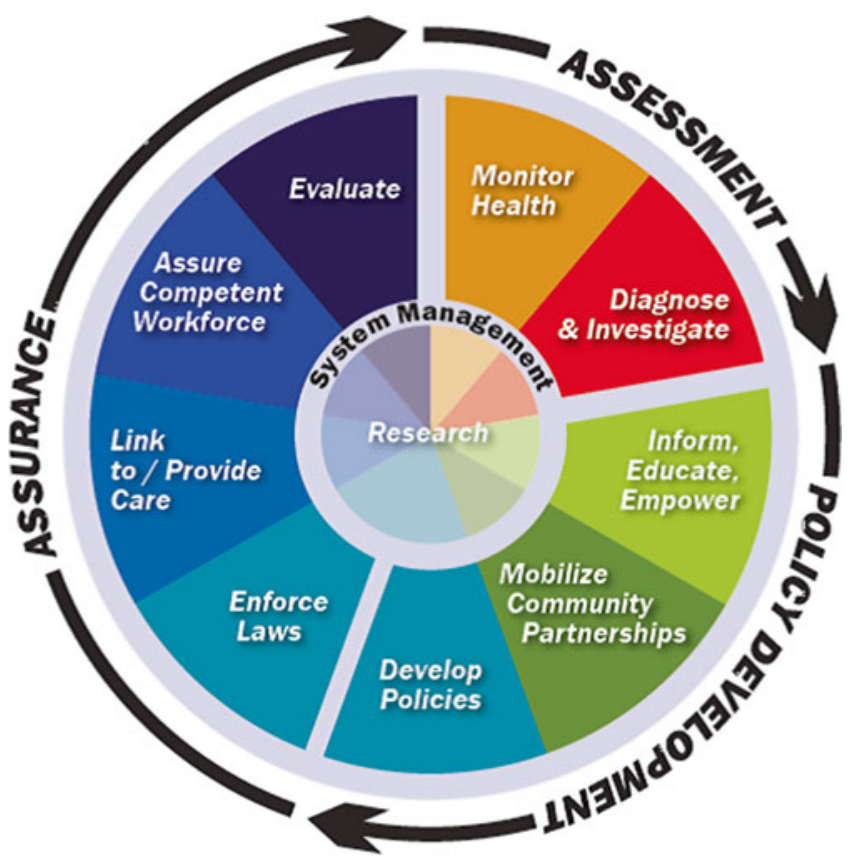

Fig. 1.1 Essential Public Health Services. (1) Monitor health status to identify community health problems. (2) Diagnose and investigate health problems and health hazards in the community. (3) Inform, educate, and empower people about health issues. (4) Mobilize community partnerships and action to identify and solve health problems. (5) Develop policies and plans that support individual and community health efforts. (6) Enforce laws and regulations that protect health and ensure safety. (7) Link people to needed personal health services and assure the provision of health care when otherwise unavailable. (8) Assure competent public and personal health care workforce. (9) Evaluate effectiveness, accessibility, and quality of personal and population-based health services. (10) Research for new insights and innovative solutions to health problems (From Public Health Functions Steering Committee 1994. Essential Public Health Services. Available at http:// www.cdc.gov/nphpsp/essentialServices.html)

Public health is the science and the art of preventing disease, prolonging life, and promoting physical health and efficiency through organized community efforts ... and the development of the social machinery which will ensure to every individual in the community a standard of living adequate for the maintenance of health (Winslow 1920).

Even more succinctly, the U.S. Institute of Medicine (IOM) defines public health as "what we, as a society, do collectively to assure the conditions for people to be healthy" (IOM 1988).

These two definitions highlight the importance of collective action to address the health needs of populations. Public health's population focus distinguishes it from clinical medicine's focus on individual patients, though examples like vaccination indicate that the two fields can overlap. Epidemiologists statistically aggregate the health data of individuals to provide a picture of population health, but populations ultimately originate from communities of individuals who constitute social wholes. 
Individuals in society stand in complex relations of interdependence, competition, and solidarity that can impact health in ways that transcend the individual. Thus, in addition to aggregating individual medical data, epidemiologists need to measure the impact of various social factors on health. To tackle the complex, often competing health needs of social groups, public health practitioners need to dialogue and partner with their communities. At a higher administrative level, public health officials need to manage intersectoral collaborations, navigate political processes, and formulate public health law. Four distinguishing features of public health practicethe pursuit of the collective good, a focus on prevention, the use of government or collective action, and an emphasis on an outcome-based (utilitarian) approachgenerate most of the ethical challenges public health practitioners typically face (Faden and Shebaya 2010).

\subsubsection{Core Values}

People value many things such as friends and family, material goods and resources, knowledge, and art. Some things people value are ethical virtues like courage or honesty, whereas others are ethical principles like justice and equality. People generally value what they consider important, what matters to them, and what gives their lives meaning. Public health's primary goals and commitments reflect its core values, which are rooted in health, science, and the community (Public Health Leadership Society 2002). Everyone recognizes the value of health, but public health approaches health in relation to science and the community in its endeavor to prevent disease and injury, protect the public from harm, and promote health and well-being. But seeing how science and community represent values requires a word of explanation.

The commitment to science as a value stance often becomes apparent only in relation to people who distrust science or prioritize other value commitments such as economic interests or religion. Public health values science by endeavoring to base interventions and policies on the best available data and evidence-based practices. That endeavor entails a commitment to conduct surveillance and research, because only by understanding the social burden of disease and its underlying or structural causes can public health impact the health of the entire population. The qualifier "best available" is a reminder of the need to continuously improve practice and not rely on tradition or current practices. It also reminds us that during emergencies, time and resource constraints limit the ability to gather evidence.

Public health values community in two obvious senses. First, it recognizes that the success of most health interventions depends on a community's acceptance, cooperation, or participation. Second, it recognizes that to be successful, public health must respect the community's values and gain the trust of its members. Yet there is a third, deeper sense in which community represents a value. A community is, to emphasize again, neither a statistical abstraction nor a mere aggregate of individuals but rather a network of relationships and emotional bonds between people 
sharing a life in common organized through a political and moral order (Jennings 2007). The value that best reflects this fundamental, relational character of social life is solidarity. Solidarity can remain unspoken yet operative because it forms the basis of social life and collective action. Just as communities are not mere aggregates of individuals, neither are the agencies or organizations that make the collective decisions that affect the community. Personal interests, to be sure, can motivate individuals, but the felt recognition of a common plight, that we are all in it together, underlies the collective decisions society and public health must make to solve collective problems. To say that public health values community means that it values solidarity, even when solidarity remains unacknowledged as is often the case (Dawson and Jennings 2012).

\subsubsection{Health Equity, Social Justice, and Social Determinants of Health}

As the foregoing goals, definitions, core values, and commitments of public health clearly suggest, the right to health and health equity are central, not peripheral, to public health's mission. Chapter 8 on international collaboration will examine some practical challenges in addressing the right to health and social determinants of health, so the emphasis here will be on the rationale for achieving health equity as a matter of social justice.

Despite greater individual access to health care and advances in public health, high burdens of disease remain across much of the globe. Some differences in disease burden result from genetics and some from variable risks of exposure to infectious agents and other threats, but most of the differential burden arises from social, economic, and political conditions. These conditions include poverty, lack of education, and discrimination against particular social groups and often reflect historical injustices or long-standing systemic, structural deficiencies. Collectively, these conditions have come to be known as social determinants of health (Blane 1999). Greater access to individual health care can mitigate their effect, but an adequate response to them requires concerted public action to address their underlying causes.

Whether comparing countries or groups within countries, social stratification by social determinants correlates with differences in health status (Marmot 2007). These health differences have aroused widespread concern, but how one defines them significantly affects public health practice (Braveman 2006). In particular, distinguishing health disparity from health inequity is critical. As a comparative indicator of health status, health disparity is a neutral, epidemiologic term that need not imply an ethical obligation to remedy. Health disparities, however, can and frequently do reflect underlying inequities. WHO defines health inequities as health differences that are "socially produced; systematic in their distribution across the population; and unfair" (WHO 2007). Terms like "inequity" and "unfair" are ethical terms that imply an obligation to redress an injustice. Justice has a range of mean- 
ings that include giving people what they deserve or are owed and distributing goods and services fairly. Justice in a medical context often involves the individual's access to health services. In public health, discussions of health equity usually involve questions of how to distribute health benefits fairly or how to achieve better health outcomes among communities or groups that suffer health inequities. Attaining greater equity might involve the politically controversial strategy of disproportionally distributing resources within a population, by, for example, distributing more to those most in need. A less-controversial strategy is to improve health outcomes for all, even while devoting special efforts to those most in need. WHO defines health equity as "the absence of unfair and avoidable or remediable differences in health among population groups defined socially, economically, demographically, or geographically" (WHO 2007).

Achieving health equity is most urgent for groups who have experienced histories of marginalization and discrimination and who continue to experience higher rates of illness and premature deaths than members of the mainstream population. Especially for these groups, "social injustice is killing people on a grand scale" (WHO 2008). Realizing the goal of social justice with respect to health means achieving health equity. Doing so requires not only a fair distribution of health outcomes, it also means that "ideally everyone should have a fair opportunity to attain their full health potential" and that "no one should be disadvantaged from achieving this potential, if it can be avoided" (Whitehead 1992). For many, these goals imply that social justice obligates public health to improve any social condition that prevents people from maintaining a standard of life adequate to maintain health (Powers and Faden 2006). Although some believe that improving social conditions that affect health overextends public health's mandate, such a broad mandate is arguably consistent with both Winslow's and IOM's definitions of public health. Moreover, such a broad mandate has both nineteenth century precursors in the social medicine movement and more recent precedents in the "Health for All" strategy that emphasizes health promotion and the "Health in All Policies" strategy (Kickbusch 2003; Freiler et al. 2013). But a major milestone was reached with the 2008 report of the WHO Commission on Social Determinants of Health that sought to "marshal the evidence on what can be done to promote health equity, and to foster a global movement to achieve it" (WHO 2008). Although governments can guarantee human rights and essential services, establish policies that provide an equitable basis for health improvement, and gather and monitor data on health equity, achieving equity ultimately will depend on the cooperation of government and civil society (Blas et al. 2008).

\subsection{Ethics}

People strive to be "good," to do the "right" thing and to lead a "good life," but where do such basic, familiar moral values as good and right originate? Throughout history, religious people have explained these ideas as revelations of divine command. 
Anthropologists, however, view morals as customs that govern social interactions, and because all cultures display such customs, interpret moral practices in terms of a survival function rooted in human nature. By contrast, many social and political thinkers emphasize that moral concepts result from social conventions or agreements that are subject to deliberation and change. Governments today often consult social scientists and health experts who empirically investigate what fosters or improves human life, health, and happiness. Where science informs law and policy, it helps define in a conventional sense what we mean by good and right. In particular, public health science helps establish what is considered good for the health of populations and communities. Further below we will examine three ethical theories prominent in public health ethics that offer contrasting perspectives on the nature and basis of morality. In the meantime, we will address three general questions that a public health practitioner first approaching the study of ethics might well ask: how does science relate to ethics, what is the difference between ethics and morality, and what sort of things count as principles or basic concepts in ethics?

\subsubsection{Scientific Facts and Ethical Values}

Public health practice increasingly requires appreciation of the complementary roles facts and values play in making and justifying decisions. Observation reveals facts, while scientific research controls and manipulates the experimental context to discover causation or correlation. Data on disease burden, research on intervention effectiveness, and estimates of the resultant health benefits for the population generally inform public health interventions. Health messaging can often inform the public about the scientific rationale underlying public health interventions. Nevertheless, in the mind of the public, scientific evidence does not always invalidate or outweigh other sources of evidence or appeals to emotions, interests, and values. While public health practitioners give more weight to community health and scientific evidence, they also need to consider how the public will respond to an intervention. Successfully implementing public health actions, then, will often entail weighing the public's attitudes, interests, and values in relation to public health's core values.

Two mundane features of public health practice often serve to conceal value assumptions: shared core values and standard practice. First, sharing values can render them invisible as assumptions, until they unexpectedly become contested. Unwelcome surprises occur when interventions that presuppose core values affect stakeholders who do not share those values, as when parents refuse to have children vaccinated based on media hearsay or individuals reject a highly effective program as governmental intrusion. Avoiding such surprises begins with becoming aware of one's own value presuppositions in relation to those of other stakeholders and community members. Second, routine use of evidence-based standards can conceal underlying value assumptions. If developed and tested to address a known health problem, as is common, an intervention's purpose and effectiveness is taken for 
granted. Standard interventions, then, generally require no more justification than noting their standard status or seeing that "the facts dictated" their use. "Dictating" facts are indicators that trigger use of a standard intervention (e.g., meeting the criteria of a case definition or documenting exposure to a dangerous level of a contaminant). Such "dictating facts," more properly speaking, only indicate the appropriate intervention but cannot literally dictate that anything be done. What in the end dictate actions are the values, goals, and obligations that the standard intervention presupposes and that practitioners tacitly ratify each time they apply the standard. In other words, values, goals, and obligations, even when tacit, form a necessary bridge between knowledge and action.

Though standard practices tacitly incorporate ethical principles, they seldom raise ethical challenges. Challenges more typically arise in unusual or extreme situations where standards are not yet in place, are changing, or are competing. These situations include emergency operations, foreign cultural settings, emergent fields with innovative interventions, or periods of severe budget constraints that force prioritization of programs. In such challenging situations where no value consensus exists or where evidence does not point to a single course of action, public health ethics provides a process to determine and justify a course of action. That justification can incorporate a number of factors: evidence base for the intervention, cost effectiveness, analysis of relevant ethical rules and stakeholder values, a creative design of options or alternatives that embody these values, and a fair and transparent decision-making process that incorporates stakeholder contributions.

Recognizing one's own value assumptions in relation to those of the public will be critical for implementing new interventions wherever success depends on public acceptance. The public will not embrace interventions that embody or presuppose values that clash with community values or whose relative importance is low compared to other community values. Members of the public generally are more committed to their political views, ethical and religious values, and an intervention's impact on them personally than to scientific evidence or community impact. Public health practitioners need to recognize that no matter how compelling to them, community impact and scientific rationale seldom resonate as deeply with the public. Consequently, in communicating, public health practitioners need to supplement scientific messaging with dialogue, an appeal to common values, or enlistment of spokespersons who share the value orientation of the relevant stakeholders or community. Regarding some controversial matters, ultimate success in implementing an intervention may require building a social consensus (Ortmann and Iskander 2013).

In certain situations, untangling factual claims based on science from value judgments is critical for success. For example, suppose independent investigators have scientifically verified the level of worker exposure to a toxic chemical used in industry. Determining what level of exposure would be safe, however, remains a value judgment that depends on the degree of concern that people have about safety. Placing a higher value on safety might result in stricter controls that decrease risk for workers, but the financial costs of decreasing risks could cut industry profits or jobs, even as health costs fall. Stakeholders representing industry, workers, or public health practitioners might have different positions regarding a safe level of exposure. 
To make a good decision about a safe exposure level, the value of safety might have to be discussed and weighed in relation to business, employment, and health considerations. However, these varying positions regarding safety need not imply disregard for safety or disagreement on the underlying facts. Rather, they illustrate that conflicting value judgments can coexist despite a consensus on both the underlying facts and the importance of a particular value such as safety.

Directly addressing the value conflicts in such situations through ethical deliberation makes more sense than calling into question the underlying facts and can lead to better, fairer, and more transparent decisions. It is also important to recognize that doubting the science often represents an underlying value dispute masquerading as a scientific dispute (Brunk et al. 1991). Sowing doubt on scientific assessments merely as a tactic to oppose an evidence-based policy or recommendation undermines science. This doubt can exert pressure to test and retest results, raising the bar for scientific validity ever higher (Michaels 2008). The solution is not to litigate, as it were, the science, but to recognize that communicating risk is a social process that goes beyond science messaging and must take cultural attitudes, perceptions, and symbolic meanings into account (Krimsky and Plough 1988). Where profound value disagreements prevail, public health legitimately prioritizes its core values but cannot speak for everyone. Stakeholder views require a fair hearing, whether through media research, stakeholder analysis, or direct solicitation of input from individuals, focus groups, or public meetings. By design, a fair, transparent ethical decision-making procedure can help determine what value tradeoffs are feasible and what values may be nonnegotiable. Such a deliberative procedure can help to gain public acceptance and become part of the justification for a course of action.

To those accustomed to rigorous research methods and evidence-based standards of practice, navigating the world of ethical values and rules can be perplexing. Values, as the term itself implies, manifest valences, that is, variable degrees of commitment or estimations of importance along a continuum. Individuals rank values differently, change their rankings, and will alter their relative ranking of values in different contexts. The range of options for ethical rules are far more limited, namely, to obey or not obey. Nevertheless, the ethical rules governing particular situations also vary from country to country or even from jurisdiction to jurisdiction within a country. Despite this variability in values and ethical rules, reducing ethical judgment to mere opinion or to a consensus of opinion relative only to personal or cultural preferences would be a mistake. Ethical values and rules enjoy the approval of history, custom, law, and religious tradition, but they also find anchor biologically, psychologically, and socially in human life. Value judgments and ethical determinations, then, are not relative as much as correlative; that is, they correlate and resonate with these deeper roots of human life that we share. If humans indeed share a set of fundamental values, then ethical conflicts primarily reflect differences in prioritizing values in a particular context, rather than a fundamental disagreement about values. This point of view provides grounds for optimism about the possibility of finding a deeper basis for understanding and mutual respect, if not agreement, when ethical tensions surface. 


\subsubsection{Ethics and Morality}

Although many use the terms ethics and morality interchangeably, we will distinguish the formal discipline of ethics from the common morality that guides everyday actions and behavior. Morality refers to a society's shared, stable beliefs about what is good and bad, right and wrong. Through upbringing and socialization, each generation passes this common morality to the next. Common morality envelopes the individual like an ecosphere of shared customs, rules, and values. For most circumstances, people habitually rely on this common morality to guide their conduct, and it serves them well, just as standard practice generally serves professional practitioners well. Still, common morality can fall short where its rules conflict, where it inadequately illuminates novel moral problems, or where intense disagreement prevails among rival stakeholders. In such instances, the formal discipline of ethics offers a deliberate, systematic way of addressing troubling moral issues, conflicts, and dilemmas. Ethics can assist in:

- Recognizing ethical issues and distinguishing them from factual issues;

- Providing a vocabulary to systematically discuss ethics;

- Identifying appropriate ethical principles to guide action in a particular context;

- Using these principles to analyze actions in regard to their ethical acceptability;

- Understanding the competing moral claims and values of stakeholders;

- Designing alternative courses of action that incorporate these claims and values;

- Evaluating which alternative best fits a given context, all things considered

- Establishing a procedurally just, transparent process for decision making; and

- Justifying decisions regarding recommendations, policies, or interventions.

\subsubsection{Ethical Principles}

Principles are general categories, rules, or guidelines that form the basis of a discipline. In ethics, there are various kinds of principles and many examples of each kind. The kinds include basic ethical categories (e.g., virtues, values, or rights), ethical commands or rules of conduct (e.g., not stealing, not harming, or treating others with respect), and guidelines for weighing outcomes (e.g., achieving the greatest good for the greatest number, distributing burdens and benefits fairly, or properly proportioning benefit to harm). Ethical principles like justice or respect for autonomy are simultaneously values, ideals, and the basis for deriving rules of conduct. Such rules serve as ethical standards to evaluate past and pending actions, programs, and policy recommendations. When addressing complex or controversial issues or issues involving numerous stakeholders, many different principles can come into play. But because ethical decision making depends on context (e.g., on local circumstances, community stakeholders, and decision makers), no formula can determine the most relevant ethical principles. Nevertheless, most ethicists and practitioners 
working in a field would agree that certain principles, theories, or frameworks provide more helpful guidance for that field. Given the need for flexibility, some prefer to speak not of ethical principles but of "general moral considerations" that can provide guidance in public health practice (Childress et al. 2002). At any rate, a complex ethical challenge involving stakeholders with competing moral claims frequently demands consideration of a variety of ethical principles and theories to address the situation and justify a proposed intervention. For these reasons, it will be useful both to examine below several ethical theories used in public health ethics and to provide at the end of the chapter a framework that is generally applicable to ethical issues that arise in public health.

\subsubsection{Ethical Theories}

As used here, an ethical framework refers to a tool or approach for practically addressing ethical challenges that often includes a stepwise procedure. An ethical framework may rely heavily on just one ethical theory, but frameworks generally take a pragmatic approach that procedurally allows for using a variety of theories or principles as the issue or context demands. Whereas an ethical framework has a practical orientation, an ethical theory also addresses more fundamental questions, so-called "metaethical" questions. Does morality originate in divine command, human nature, or human convention? Is it essentially a habit, intuition, form of reasoning, or a quality or purpose of an action? An ethical theory will offer a distinct, coherent understanding of the source and nature of morality that will shape how one reasons about moral issues and determine which principles are most important. Two persons employing the same theory, however, will not necessarily reach the same conclusion about an ethical issue; much will depend on which aspects of the issue they deem most important and on how they weigh different factors. Nevertheless, because a particular ethical theory tends to favor certain principles or types of principles, using the same theoretical approach will lead to similar lines of reasoning and selection of principles.

The diversity of ethical theories does not imply their mutual opposition so much as points to the extensive range of the moral landscape and the need to illuminate its various contours. A helpful way of illuminating this landscape is to distinguish theories depending on whether they focus on the actor, the action, or the results of action. To illustrate this particular way of carving up the moral landscape, Table 1.1 describes some well-known ethical theories.

Aristotle's virtue ethics is an ethical theory that focuses on the moral character of the actor or agent (Bartlett and Collins 2011). Classic virtues are dispositions or stable patterns of behavior that lie between extremes of vice; courage, for example, lies between the extremes of cowardice and foolhardiness in taking risks. Habit and practice are necessary to develop virtues whose possession we equate with good character and that equip a person to be effective in society or an organization. Because good character translates into virtuous action that others aspire to emulate, 
Table 1.1 Ethical theories

\begin{tabular}{l|l|l|l}
\hline Theory & Agent-centered & Deontology & Utilitarianism \\
\hline Focus & Agent & Action & Result of action \\
\hline Key figure & Aristotle & Immanuel Kant & John Stuart Mill \\
\hline $\begin{array}{l}\text { Main } \\
\text { concept }\end{array}$ & $\begin{array}{l}\text { Virtues: Acquired habits, } \\
\text { skills, or dispositions that } \\
\text { make people effective in } \\
\text { social or professional } \\
\text { settings }\end{array}$ & $\begin{array}{l}\text { Duties: Ethical rules or } \\
\text { commands that constrain } \\
\text { one's action or define } \\
\text { obligations owed to } \\
\text { others }\end{array}$ & $\begin{array}{l}\text { Results: Good or bad } \\
\text { outcomes of actions and } \\
\text { policies or their } \\
\text { beneficial or harmful } \\
\text { effects on individuals } \\
\text { and society }\end{array}$ \\
\hline Examples & $\begin{array}{l}\text { Honesty, courage, } \\
\text { modesty, trustworthiness, } \\
\text { transparency, reliability, } \\
\text { and perseverance }\end{array}$ & $\begin{array}{l}\text { Ethical and religious } \\
\text { commandments, } \\
\text { obligations to seek justice } \\
\text { or respect persons and } \\
\text { their rights }\end{array}$ & $\begin{array}{l}\text { Burdens, risks, harms, } \\
\text { or costs versus the } \\
\text { benefits, advantages, or } \\
\text { savings resulting from } \\
\text { interventions or policies }\end{array}$ \\
\hline $\begin{array}{l}\text { Ethical } \\
\text { action }\end{array}$ & $\begin{array}{l}\text { Doing what a virtuous } \\
\text { person would do in a } \\
\text { given situation }\end{array}$ & $\begin{array}{l}\text { Fulfilling an obligation or } \\
\text { duty owed to oneself or } \\
\text { society }\end{array}$ & $\begin{array}{l}\text { Maximizing the net } \\
\text { balance of benefits over } \\
\text { harms }\end{array}$ \\
\hline Uses & $\begin{array}{l}\text { Assessing skills and } \\
\text { capacities needed for } \\
\text { success in a community, } \\
\text { organization, or } \\
\text { profession }\end{array}$ & $\begin{array}{l}\text { Establishing compliance } \\
\text { rules and regulations, and } \\
\text { setting standards for } \\
\text { evaluating actions and } \\
\text { behavior }\end{array}$ & $\begin{array}{l}\text { Conducting population- } \\
\text { level cost-benefit, } \\
\text { risk-benefit, or } \\
\text { cost-effectiveness } \\
\text { analyses }\end{array}$ \\
\hline
\end{tabular}

we tacitly invoke virtue ethics whenever we ask how an outstanding public figure or health leader would handle a situation. In a modern professional context, virtues also include the skills the profession has identified that lead to success in that profession and which professional education and training instill in practitioners. Once established, virtues readily become the standards of obligation and accountability to evaluate professional performance and function similarly to the rules and principles of duty discussed below. Holding public health institutions accountable for the professional competence of their employees illustrates virtue ethics (Public Health leadership Society 2002). More recently, the capabilities approach has exploited the potential of virtue ethics to guide decisions about policy or interventions in a way that goes beyond matters of professional training and responsibilities. This approach takes a broader developmental view of human agency and capacity building. It conceives health as a fundamental capability necessary for individuals to succeed in society, one on which many further capabilities depend (Sen 2009; Ruger 2010).

An ethical theory that focuses on action or, more properly, the rules governing action, is deontology. The word deontology comes from the ancient Greek word, deontos, which means duty. Because duties oblige us to obey rules that govern actions or conduct, they bind or constrain the will ahead of action. In judging whether an action is right or wrong, deontology ignores consideration of harmful or beneficial consequences and relies on these rules of duty to serve as the standard of judgment. People usually have rules of duty or obligation in mind when they speak of ethical standards or worry that standards are breaking down. Examples of these rules include religious commandments to honor parents, not lie, or not steal and 
rules of social interaction such as treating people fairly, doing them no harm, or respecting their rights. Rights often are said to stand in reciprocal relation to duties. Thus, the right to free speech presupposes a duty to respect the right of others to speak or the public health obligation to ensure conditions for maintaining health presupposes a right to health.

Deontology as a theory owes most to Immanuel Kant's view of the "good will" and his closely linked account of autonomy. A person of morally good will does the right thing for its own sake, which means acting purely for the sake of duty. Duties are moral rules or laws that bind the will and limit the scope of action. For Kant, basing decision for one's action solely on duty without regard to the potential good or bad consequences of the action is the only legitimate basis for moral action. Kant even goes so far as to say that "a free will and a will under moral laws are one and the same" (Gregor et al. 2012).

Kant conceives duty as the quintessential expression of autonomy, which may come as a surprise to those who equate autonomy with rational free choice or even just following one's preferences without interference. However, the meaning of autonomy for Kant derives from its literal meaning in Greek, autos (self) and nomos (law); namely, self-legislating. Autonomy enacts from within the moral rules and principles that bind the will and guide action. However, not every self-originating impulse should be obeyed; only actions conceivable as universal laws morally bind the will. Morally laying down the law for oneself entails legislating for everyone, but universally legislating does not mean asserting one's will over others. Nor does it mean that the ethical content of a moral law or duty is valid eternally and everywhere. Rather, it refers to the "categorical imperative" an unconditional requirement for an action to be moral. To qualify as a duty, a rule that commands action must apply to every rational person. Stealing, for example, could never qualify as a duty, because a situation where everyone steals from everyone else would undercut the one-sided advantage of stealing that the thief hopes to exploit. Although selfdirected, autonomous action is necessarily other-regarding.

Kant maintains that the categorical imperative can be expressed in two other ways equivalent to universality, namely, "respect for humanity" and a "kingdom of ends" (Gregor et al. 2012). In each, this other-regarding dimension of autonomy is evident. Respecting humanity means never treating persons as mere means or objects but always treating them as ends, that is, regarding them as fellow autonomous agents. Autonomously agreeing on actions, interventions, or policies requires that decision makers mutually consider and understand their reasons for action and be willing to abide by the rules derived from these reasons as laws they collectively impose upon themselves (O'Neill 2002).

The idea of a fellowship of mutual consideration comes out most clearly in Kant's concept of a kingdom of ends. This concept is really the ideal of a systematic union or commonwealth of autonomous individuals making laws that apply to everyone. This ideal presupposes that ethical deliberation places respect for others as ends, as autonomous agents, above self-interest. The core idea is that we only consider actions that could gain acceptance by a community in which all see themselves as sovereigns who lay down universal laws binding on themselves and others. 
The hope is that the body of law governing society progressively embodies this ideal. Such mutual regard in laying down the moral laws that will bind one's actions differs significantly from insistence on noninterference with individual free choice, let alone with personal preferences. Conversely, the aspiration behind Kant's view of autonomy harmonizes well with the public health obligation to address collective problems through collective action.

For utilitarianism, judging the rightness of an action depends on an estimation of its subsequent practical outcome or result rather than on its conformity to principles of duty. Utilitarianism considers ethically best that course of action that will result in the greatest net benefits over harms. A utilitarian approach underlies cost-benefit analyses that weigh an intervention's costs (risks, harms, burdens, or disadvantages) against its benefits (advantages, utility, improvements, cost savings). In addition to its focus on consequences, utilitarianism is egalitarian, communitarian, and scientific in outlook. It is egalitarian in considering everyone's benefit and equally weighting each person's good, as opposed to privileging certain people. It is communitarian in attempting to increase benefits to society rather than individuals, seeking the "greatest good for the greatest number." It endeavors to be scientific by quantifying harms and benefits, accounting for probability, and calculating net benefit. Calculating net benefits over harms is less problematic when relevant factors employ a common scale of measurement, for example, weighing the financial costs of treating a disease with the cost savings from preventing that disease. Comparing different outcomes (e.g., financial costs versus quality-adjusted life years) sometimes involves difficult judgments about the relative value of each outcome. Because the utilitarian approach seeks to determine and promote the collective good based on aggregate measures, it readily lends itself to justifying public health interventions.

\subsubsection{Law Versus Ethics}

Laws share certain deontological features with ethical principles of action (and with religious commandments). They all define one's obligations or duties and typically take the form of rules or commands regarding what one should or should not do. They can lay down positive requirements to fulfill but more commonly establish parameters that prohibit certain actions or constrain liberty in some way. Laws do not differ from ethical rules primarily based on content, because an ethical rule can become a law without changing the rule's content. For Kant, at least, the crucial difference between ethics and law concerns one's reason for obeying; namely, whether one acts purely voluntarily out of a sense of duty or merely in external conformity with duty, either to appear to be moral or out of fear of penalty or punishment. Laws are rules enforced by penalty or punishment, which many people might otherwise break. Society can tolerate the flouting of some rules, but disobedience of more important rules can disrupt society or create danger. For these reasons, society establishes and enforces laws regarding socially important matters, not 
leaving their compliance up to individual prerogative. An ethical rule's enactment as law, therefore, implies agreement by society or the law's enactors on the importance of strictly regulating the behavior the law governs. Law can be a blunt instrument that effectively compels compliance, which suffices to satisfy the reasons for its enactment, even if it cannot coax voluntary obedience from an inward sense of duty.

In theory, deontologically evaluating a past or proposed action is a straightforward binary determination of compliance or noncompliance with a legal or ethical rule. In practice, however, defining a rule's scope or determining exactly which actions fall under it can prove difficult. Moreover, when different rules apply, determining which should take precedence often becomes problematic, especially when they conflict. Lying to protect a relative, for example, can put the duty to speak truthfully into conflict with familial obligations. Determining which rule takes precedence can involve reasoning clearly from ethical principles, weighing the underlying values embodied in the law, or considering the practical impact of the intervention in context. Because laws demand compliance, they are more rigid. Additional legal stipulations can prioritize or specify how to apply laws in certain situations, but doing so increases their complexity. Ethical guidelines operate more flexibly than rigid, compulsory laws and more readily accommodate compromise. With ethical guidelines, decision makers can consider and rank the underlying values the ethical rules serve to promote. Doing so allows for trade-offs between competing ethical considerations and for deciding which values it makes sense to prioritize in the given context. Conversely, law's comparative rigidity can be a virtue where only stricter oversight and enforcement will ensure compliance and establish order.

Across cultures, legal, ethical, and religious rules prohibiting basic offenses such as lying, theft and murder show considerable overlap. However, cultures vary in exactly which rules are matters of individual choice and which are matters of legal enforcement and punishment. This variability also applies to the status of rules and standards governing research on human subjects. Even within a country, significant variability can prevail in whether human subjects' research rules and standards are legal regulations or ethical guidelines (U.S. Department of Health and Human Services 2015). Some see the lack of legal regulation as a breach in protections, but others prefer guidelines, arguing that regulations tie reviewer hands, making it more difficult to make trade-offs or nuanced judgments based on moral discernment of the particulars of each case (Verweij and Dawson 2009). Because each approach offers advantages and disadvantages, political culture and local context must ultimately decide whether human subjects' research rules exist as enforceable regulations or ethical guidelines.

Regardless of whether it takes the form of guidelines or law, research ethics will govern only a fraction of the ethical issues that the field of public health must address. In many areas of public health practice, there are no specific ethical guidelines or regulations. To address ethical challenges in these areas or to address emergent challenges, the ethical practice of public health therefore requires the ability to use general ethical frameworks. Such frameworks can employ checklists of questions and stepwise procedures. However, because novel challenges continually 
emerge and changing contexts introduce nuances no set of rules can anticipate, public health professionals ultimately need to practice ethical decision making over time in order to cultivate moral judgment and discernment.

By laying down and enforcing what may, must, or cannot be done, legal rules function as boundaries of acceptable behavior. Ethics, science, budgets or politics, each in its own way, also can restrict the scope of action. Public health practitioners and officials therefore first need to conduct a feasibility analysis to determine the relevant limits on possible interventions or policies. Determining these limits seldom will restrict the scope of action to a single possible course. Given multiple possibilities, most people will aspire to the best course of action beyond the legal floor of minimally acceptable behavior yet within the other relevant limits. As a result, the ethical challenges public health practitioners face seldom involve stark choices between right or wrong, good or evil. A good feasibility analysis will have ruled out any unethical or illegal options or alternative courses of action in advance. Rather, the tough choices more frequently involve selecting the best alternative from among competing goods, each of which to a greater or lesser degree realizes the public health goal and embodies relevant stakeholder values.

Whereas determining and complying with the various limits on action is largely an analytic process, designing alternatives is a synthetic, creative process. Alternatives should all realize the public health goal and incorporate the perspectives and values of subject matter experts and relevant stakeholders. Deciding upon the best alternative must take into account how it will realize the public health goal in a particular context and with respect to the stakeholders. For example, advocating contraceptives to reduce unwanted teen pregnancy might seem to promise success based on efficacy studies, but ethical controversy could render such a program less than optimal in some contexts. Political culture or social norms can confer partisan advantage or disadvantage to some alternatives, while other alternatives may enjoy an advantage because of the experience and expertise of a health department. Whatever alternative practitioners finally choose, their choice will presuppose a prioritizing of values. The foregoing account highlights why public health practitioners need to see ethics as something more than a compliance matter. It transcends compliance because public health ethics also involves practical decision making, which should include stakeholder analysis, the incorporation of stakeholder values in the design of alternatives, and a fair, transparent deliberative process to evaluate alternatives.

\subsection{Public Health Ethics}

Compared with more established fields of practical ethics such as clinical ethics, research ethics, and bioethics, the field of public health ethics is relatively new. Consequently, many public health practitioners may be better acquainted with these more established fields than with public health ethics. In particular, practitioners may already be acquainted with the four principles these fields rely on for ethical evaluation: beneficence, nonmaleficence, respect for persons (autonomy), and 
justice (U.S. Department of Health, Education, and Welfare 1979; Beauchamp and Childress 2012). Being applicable to health and research, these four principles also are relevant to public health, but having arisen to address issues in other fields, they need to be adapted to a public health context. Even then, they still fall short in addressing the ethical challenges that arise in public health. Examining these related ethics fields and showing how the four principles fit into a public health context can serve by way of contrast to indicate what is distinctive about public health ethics.

\subsubsection{Research Ethics, Clinical Ethics, and Bioethics: Principlism and the Four Principles}

Research ethics entails the wider notion of scientific integrity but is best known and most developed in relation to medical research involving human subjects. The development of human subjects' research ethics guidelines can neither be divorced from breaches of ethical conduct in human subjects' research nor wholly reduced to a reaction to these events. But beginning with the Nuremberg Code (1947), balancing risks and benefits to research subjects and getting their informed consent have been cornerstones of international research ethics guidelines. Far more influential than the Nuremberg Code, the Declaration of Helsinki from the World Medical Association (WMA) is a fundamental document in international human subjects' research ethics guidelines. Its initial 1964 version included provisions for proxy consent for those with diminished autonomy. Its 1975 revision called for review of research by an independent committee, now known as an ethics review committee (WMA 1964, 1975, 2013). The use of such committees began spreading under the aegis of WHO and then in response to the HIV/AIDS pandemic, as the number of large-scale vaccine and drug trials grew in developing countries. In the United States, research regulations set forth in the Common Rule govern ethics review committees as well as all human subjects' research that receives U.S. government funding (U.S. Department of Health and Human Services 2009). In the United States, a standing ethics review committee generally functions within a specific governmental or university institution and therefore is referred to as an institutional review board (IRB). Beginning in 1982, the Council for International Organizations of Medical Sciences (CIOMS), in collaboration with WHO, proposed international ethical guidelines for biomedical research involving human subjects (CIOMS 2002).

Our discussion of these documents has only highlighted key provisions of what is required to ensure the safety of human subjects. CIOMS's most recent research guidelines (2002), for example, contain more than 60 pages of text, explanation, and commentary. But ensuring ethical conduct and scientific integrity in research requires more than the oversight function of ethical review committees. It also requires extensive training not only in research ethics but also in a number of related 
areas. Training and guidelines should cover, among other things, mentoring of junior researchers, authorship and publications policy, conflicts of interest that arise in partnerships and collaborative science, and data acquisition, management, sharing and ownership. Ethics training can help develop moral judgment. The hope is that training and application will enable practitioners to reason about new, difficult, or ambiguous cases in morally discerning ways.

Clinical ethics address the ethical issues that arise in clinical practice. Until the advent of bioethics, medical professionalism emphasized the health care provider's obligation to prioritize the patient's welfare, the health care provider's professional judgment about what would most benefit the patient, and the importance of establishing patient trust. The traditional model of clinical ethics was frankly paternalistic. Under the influence of bioethics, many health care providers began embracing a more patient-centered model of care that emphasized patient autonomy and informed consent. This patient-centered model conceives care as a contract between patient and provider. The emphasis on contracts strikes some as an inappropriate consumerist model that undervalues professional judgment and undermines patient trust in the medical profession. Tensions between these two models have led to a compromise that reasserts the importance of medical professionalism and clinical judgment, while acknowledging the importance of respecting patient autonomy (ABIM Foundation et al. 2002).

Bioethics has a range of meanings, the first of which applies to ethical issues brought about by advances in biomedicine and biotechnology. Ethical issues that arise from using life-sustaining technologies in end-of-life and beginning-of-life care epitomize this sense of bioethics. But bioethics also arose in response to medical paternalism and to the abuse of human subjects in medical research. Bioethics has championed informed consent, patient autonomy in doctor-patient relationships and the safety of human subjects in research. However, many bioethicists think the focus on clinical ethics and on personal autonomy unduly restricts bioethics' purview. They advocate a more holistic, social justice approach in bioethics, which has been referred to as "population-based bioethics" or "integrative bioethics" (Sodeke 2012). It can be argued that this expansion of bioethics beyond clinical ethics into population issues moves bioethics into the arena of public health ethics (Callahan and Jennings 2002).

Principlism came into being in a 1979 document called the Belmont Report (U.S. Department of Health, Education, and Welfare 1979). The report was the work of the U.S. National Commission for the Protection of Human Subjects of Biomedical and Behavioral Research, which convened in 1974 partly in response to the exposé of the U.S. Public Health Service Tuskegee Syphilis Study. The Belmont Report became the basis for revising 45 CFR 46, the so-called Common Rule, part of the legally binding U.S. Code of Federal Regulations, governing the protection of human subjects (U.S. Department of Health and Human Services 2009). The Belmont Report clearly explained the underlying ethical principles that informed existing regulations and provided an ethical framework for thinking about subsequent regulations. Principlism has remained the predominant ethical framework in biomedical ethics (Beauchamp and Childress 2012). Its explanatory groundwork 
accounts for much of its success, but its relevance to medicine and research, the prestige that attaches to these fields, and its compatibility with liberal individualism also have played a role.

Beneficence (doing good) and nonmaleficence (doing no harm) date back to the Hippocratic Oath as medical principles. Collapsing them both into beneficence, as the Belmont Report does, underscores the practical consideration that biomedical decisions generally aim to optimize net benefit over harm, rather than to maximize only benefits or minimize only harms or risks. However, these principles are distinct, not mere opposites. Not doing harm has a certain priority (first, do no harm), because not benefitting someone seems a less serious offense than doing that person harm. That priority partly reflects the human tendency more readily to forgive overlooked benefits (errors of omission) than deliberate actions resulting in harm (errors of commission).

Justice has several meanings that include due process and fair deliberative procedure, properly assessing what people are owed or due, and equitable distribution of burdens and benefits. According to philosophic tradition, justice has always functioned dually, applying to individuals but more importantly serving as an overarching principle for adjudicating competing claims in relation to the group or to other members of society. The phrase, "social justice," then, is redundant but in political contexts marked by individualism serves as a reminder of justice's social dimension. In fact, this phrase came into vogue in public health circles to counter the ideology of "market justice," which views the equal access of individuals to the free market as a valid, reliable, and preferred means for sorting out issues of economic and social justice (Beauchamp 1976). The notion of health equity, which compares different groups, primarily refers to this social dimension of justice, although denial of access to health care, a contributing factor to health inequity, violates what the individual is owed.

Respect for persons emphasizes that individuals, as agents in charge of their own lives and bodies, have the right to make decisions and choices free from undue interference. Respect for persons forms the basis of informed consent, namely, the right of patients and human research subjects to be informed of, and to assent to, medical or research procedures they might undergo, especially procedures that pose potential harm or risk. Conducting research on human subjects or performing medical procedures on patients without their prior knowledge or consent in most cases violates their personal autonomy. However, health professionals have a special (i.e., paternal) obligation to look out for the welfare of people with diminished decisional capacity — such as those in a coma or the very young-and to protect them from harm.

These four principles were originally conceived as prima facie principles, that is, each expressed a self-evident though not absolutely binding obligation and none had an inherent priority over another. However, in many Western countries and in the United States in particular, respect for persons has dominated discussion in bioethics, clinical ethics, and research ethics where it often takes precedence as a moral consideration over the other principles. This ascendancy most likely reflects the high value that these countries place on liberty and freedom. At any rate, in public 
discourse generally and in public debate about public health interventions, respect for persons often amounts to an insistence on noninterference with individual free choice or with personal preferences. Although Kant's other-regarding idea of moral autonomy, harmonizes well with collective decision making, the insistence on noninterference with personal choice often creates impediments to the implementation of public health interventions. In part for this reason, the social justice movement has had to challenge the emphasis on respect for persons in order to promote the public good and health equity.

\subsubsection{Contrast between Clinical Ethics and Public Health Ethics}

Table 1.2 contrasts the individual focus of clinical ethics with the community/ population focus of public health ethics. Because public health and clinical practice can overlap, the items in the respective columns represent tendencies along a continuum rather than stark opposites. Where separate agencies carry out public health services and medical care, these contrasts may be more pronounced. The overlap between public health and clinical practice makes it even more important to highlight their differences to bring out distinctive features of public health ethics.

The table makes clear that the Belmont principles of beneficence (seeking benefits), nonmaleficence (avoiding harm), respect for persons, and justice remain important in public health, but must be extended to accommodate the broader scope

Table 1.2 Comparison of areas of focus/tendency in clinical ethics and public health ethics

\begin{tabular}{l|l}
\hline Clinical ethics focus/tendency & Public health ethics focus/tendency \\
\hline $\begin{array}{l}\text { Treatment of disease and injury } \\
\text { professionals }\end{array}$ & Prevention of disease and injury \\
\hline $\begin{array}{l}\text { Individual benefit seeking and harm } \\
\text { avoidance based on health care provider's } \\
\text { fiduciary relation to a patient }\end{array}$ & $\begin{array}{l}\text { Rocial, community, or population benefit } \\
\text { seeking and harm avoidance based on collective } \\
\text { action }\end{array}$ \\
\hline Respect for individual patients & Relational autonomy of interdependent citizens \\
\hline $\begin{array}{l}\text { Professional duty to place the interests of the } \\
\text { patient over that of provider }\end{array}$ & $\begin{array}{l}\text { Duty to the community to address health } \\
\text { concerns that individuals cannot solve and that } \\
\text { require collective action }\end{array}$ \\
\hline $\begin{array}{l}\text { Authority based on the prestige and } \\
\text { trustworthiness of the physician and the } \\
\text { medical profession as a whole }\end{array}$ & $\begin{array}{l}\text { Authority based on law, which is a principal tool } \\
\text { of public health policy for creating health } \\
\text { regulations }\end{array}$ \\
\hline $\begin{array}{l}\text { Informed consent sought from an individual } \\
\text { patient for specific medical interventions }\end{array}$ & $\begin{array}{l}\text { Community consent and building a social } \\
\text { consensus through ongoing dialogue and } \\
\text { collaboration with the public }\end{array}$ \\
\hline $\begin{array}{l}\text { Justice concerns largely limited to treating } \\
\text { patients equally and ensuring universal } \\
\text { access to health care }\end{array}$ & $\begin{array}{l}\text { Central concern with social justice regarding } \\
\text { health and achieving health equity }\end{array}$ \\
\hline
\end{tabular}


of public health interventions. This broader scope entails many types of professionals, interventions and policies that display a political and social dimension, and a wider range of activities such as community engagement, intersectoral collaboration, collective decision making, and governmental administration. As a result, prevailing political philosophies and culture will necessarily shape the way public health functions. The crucial point is that differences of scale that produce a higher order of complexity also produce qualitative differences that introduce different patterns of causation. Among other things, this means that social factors do not merely represent aggregated individual factors and so cannot always be addressed in the same way as individual factors.

\subsubsection{Individual Versus Relational Autonomy}

For understanding what is qualitatively distinct about public health, the contrast between respect for individual persons and the relational autonomy of community members is key. Respect for persons upholds an individual's right to make independent decisions free from undue pressure, but relational autonomy emphasizes that individual actions occur in the context of other people whom these actions will affect. The potential harmful impact of individual action on the welfare of others sets a limit to individual action. Relational autonomy draws attention, then, to the interdependence of people living in communities and to the solidarity that arises from the emotional bonds that shared lives create. Anthropology teaches that people always find themselves in a network of social relations, while evolutionary biology has shown how profoundly people are built from the physiological ground up as sociopolitical beings. Because it presupposes the social context of language and reasoning ability, individual autonomy also depends developmentally on relational autonomy. That is, people only become autonomous through relations and interactions with others. As African humanism (ubuntu philosophy) epitomizes it, umuntu ngumuntu ngabantu, "a person is a person through other persons" (Louw 2008). Familial and communal deliberate processes are foundational for the development of individual autonomy and provide an even deeper basis for collective decisions than the type of solidarity that comes to the fore in crises or in the face of common predicaments. Kant would reject any suggestion that developmental context, emotional bonds or feelings of solidarity underpin moral autonomy. Nevertheless, moral autonomy and relational autonomy both display an inner-directed, but other-oriented feature that readily aligns with collective decision making.

These points about the foundational character of social relatedness, solidarity, interdependence, and communal decision making do not readily align with certain features of social contract theory, on whose principles liberal democracy is based. Whereas virtually every other political tradition conceives the sociopolitical realm as a natural feature of human life, social contract theory posits humankind's original state, the state of nature, as one of solitary individualism. In this view, society or at 
least civil society come into existence voluntarily through a contract that creates government through the consent of the governed (Riley 1982). Although never seriously advanced as a scientific account of society's origins, social contract theory nevertheless has exerted a powerful influence as a political founding myth. As such, it has made personal liberty, free choice, and consent of the governed presumptive values of societies whose governing political philosophy rests on social contract theory. By "presumptive," we mean that the value, norm, or claim is assumed to be valid or have priority, so that the onus is on the person who objects to the presumption to justify a different value, norm, or claim.

\subsubsection{Personal Autonomy as a Presumptive Value of Liberal Democracy}

Personal autonomy in a clinical and research context generally means respect for the patient's right to receive an explanation of a medical procedure or research intervention, to be informed of any potential benefits or harms, and to freely choose whether to accept the procedure or participate in the research. More generally and in other contexts, personal autonomy has come to mean an insistence on liberty, free choice, and noninterference with personal preferences. Personal autonomy in this more general sense owes more to John Stuart Mill's nineteenth-century views on liberty than to Kant's eighteenth-century idea of autonomy (O'Neil 2002; Dawson 2011). An important aspect of Mill's view of liberty is the "harm principle," which holds that "the only purpose for which power can be rightfully exercised over any member of a civilized community, against his will, is to prevent harm to others" (Mill 1989). What people choose to do regarding themselves is no business of government. Interfering with this private sphere of self-determination constitutes governmental paternalism. This interference diminishes the sphere of liberty that affords individuals the chance to direct their own lives and develop their talents and character to the highest degree. A chief advantage of democratic society, one that benefits the entire society, is the creative social dynamism that emerges from the synergism between individuals who are developing their talents and abilities.

Arguably, the primary aim of the harm principle is to promote the kind of individual self-development that benefits society rather than to champion every exercise of free choice. At any rate, some have sought to distinguish this edifying version of personal autonomy from an all-encompassing version that demands undue deference to any and all personal choices and preferences merely because they are personal (O’Neill 2002; Dawson 2011; Powers et al. 2012). Presuming, or insisting on, the validity of personal autonomy makes more sense in the delimited context of medicine and biomedical research on human subjects where an individual's body is the focus of activity. It makes less sense in the far wider sphere of public health activity where social interactions and the interdependence of people come into play. Absolutizing personal autonomy in the sphere of public health would give effective 
veto power over every collective decision aimed at the public good to any individual who felt constrained by that decision. A more moderate version might distinguish levels of importance of personal choices and exercises of liberty. A collective decision concerning the public good could override some personal choices and limit liberty, even when they did not involve direct harm to others. Such decisions, when made in the context of a fair, transparent process of ethical deliberation involving stakeholders, are more likely to get buy-in from a community and less likely to be labeled paternalistic.

Because public health considers the relation between individuals and the collective good, it necessarily has a political dimension. How a country's political culture balances this relation will drive and constrain public health practice and so shape the nature of the ethical frameworks that are appropriate to a country's politics (Hyder et al. 2008). In the brief history of public health ethics, the most important ethics frameworks have emerged in the political context of liberal democracy. Many of these frameworks reflect the tensions between public health's obligation to act collectively for the common good and the presumptive value of personal autonomy. The principle of least infringement and Kass's code of restraint illustrate the effort to mediate such tensions (Kass 2001). The code of restraint strives to balance autonomy claims against the obligation to safeguard community health by determining what intervention most effectively protects health while minimally infringing on liberty. In a liberal political context that recognizes Mill's harm principle, this strategy justifies the trumping of personal autonomy as long as imminent harm threatens the populace, for example, in a deadly outbreak of contagious disease. But where the threat of harm to others is indirect or not immediate, as with the obesity epidemic, the harm principle less readily justifies a liberty-limiting intervention such as banning or taxing certain foods. Utilitarian approaches that weigh the health advantages of intervention and the disadvantages of obesity clearly support obesity intervention, but limiting interventions to those that do not restrict personal choices also have limited effectiveness. In Chap. 6, Jennings considers the relative merits of these approaches in his overview of the ethical issues in environmental and occupational public health. His discussion raises the question of the extent to which an ethical framework should adapt itself to the presumptive values of the political context or should reflect the nature of the practical field under investigation. To some extent, it must do both.

The three-step framework offered in the next section is designed to guide decision makers, through questions, to assess the ethical dimensions of a case, including which moral considerations (e.g., population utility or liberty) may have more weight than others, given the issue or context. This contextual approach provides the flexibility and starting point for deliberation to accommodate the issues globally and to uncover the varying perspectives of stakeholders with potentially different presumptive moral norms (e.g., solidarity versus individual rights). 


\subsection{Ethical Frameworks}

What at first glance demarcates public health ethics from related fields of health ethics are the ethical problems that public health professionals typically encounter in their practice and the ethical frameworks used in practice to address these problems. Regarding these ethical problems, this casebook offers a representative, but not exhaustive, sample. Regarding ethical frameworks, this chapter has suggested two competing criteria for choosing. On the one hand, ethical frameworks should be grounded in their topics. Dawson (2011) expresses the point succinctly by arguing that public health should be the foundation of public health ethics. Accordingly, we have presented a view of public health ethics that builds on the definitions of public, health, and public health, and on the goals of public health practice. But we have also defined ethics and indicated how public health ethics draws on numerous ethical theories and can provide a moral guide grounded in the norms of benefiting others, preventing harms, and providing utility. We have pointed out its distinguishing principles based on the facts of community and interdependence. Lastly, we have situated public health ethics within the process of ethical decision making about which options are the most justifiable means to achieve public health goals in a particular context. In the end, grounding public health ethics in public health may require public health leaders to have the courage to advocate public health values and goals, even when that position is unpopular. Such a stance may be justified, for example, where the feasibility of a much-needed public health intervention requires a long-range strategy to change social norms or build social consensus.

On the other hand, precisely because public health itself is practical, pragmatic, and community oriented, an ethical framework designed for it must accommodate itself to a country's presumptive values and political culture. This consideration illustrates that the feasibility of public health interventions usually depends on their alignment with the political culture, while their success usually implies public acceptance. Many established frameworks, like that of Kass, seem designed with a liberal political context in mind that gives presumptive weight to individual liberty, which may limit the range of interventions that can be justified. Newer approaches to ethical analysis in public health place more emphasis on social values like equity and solidarity, although these newer approaches often are difficult to put into practice (Lee 2012). In addition, while newer approaches may offer clear reasons to justify a broader range of interventions, the reasons may be less persuasive if they do not consider the presumptive values in context. For example, in Chap. 3, Daniels discusses the ethical conflicts that arise during pandemics between the standard goal of improving population health and emergency contexts that demand allocating scarce resources in a way that treats people fairly. He asks, if in the pandemic context we believe that saving the most lives trumps giving priority to those who are sickest, can we justify revising the usual priority given to the sickest in health care?

Arguably, what would be most useful is not a set of frameworks designed for specific presumptive values, but, rather, a framework that can accommodate any presumptive values and consider them in relation to values rooted in public health 
or in context. The three-step framework that follows is a straightforward tool to help practitioners analyze the ethical tensions in a particular context. It addresses Daniels' tough question directly by considering health care's presumptive prioritization of the sickest in relation to the public health value of saving the most lives in a pandemic.

\subsection{A Three-Step Approach to Public Health Decision Making}

We offer the following framework, drawn from public health practice and described by Bernheim et al. (2007), as an example of an analytic tool that can guide decision makers through reasoning and deliberation. It is not meant to introduce a rigid application of ethical principles, nor does it presume that any one moral norm has greater weight that trumps other norms. Instead, the questions are designed to help decision makers clarify whether a particular moral norm (e.g., solidarity or liberty or equity) is weightier than others in context, and if so, then strong reasons must be offered to override the presumptive moral norm. For example, during an epidemic, equity may carry presumptive weight and trump other moral norms in some contexts. Ethicists at the Joint Centre for Bioethics offered the following insight from the SARS experience:

In the case of an epidemic, it is important to control the spread of the disease, but as much attention should be paid to the rights of the noninfected patients who need urgent medical care. There may be as many people who died from other illnesses and could not get into hospital as there were who died from SARS. Equity is required in the amount of attention given to a wide array of people, including patients with and without SARS. Accountability for making reasonable decisions, transparency and fairness are expected .... (Singer et al. 2003)

The questions clarify the relevant factors, such as stakeholder claims, alternative actions, and possible justifications for deciding on one course of action.

\subsubsection{An Approach to Ethical Analysis and Justification in Context}

Step I: Analyze the Ethical Dimensions of the Public Health Issue and Context

- What are the risks, harms, or concerns?

- What are the appropriate public health goals in this context?

- What is the scope and legitimacy of legal authority, and which laws and regulations apply?

- What are the moral norms and claims of stakeholders, and how strong are they? 
- Are precedent legal or ethical cases relevant for identifying the presumptive moral norms?

- Which features of the social-cultural-historical context apply?

- Do professional codes of ethics provide guidance?

Step II: Formulate Alternative Courses of Action and Evaluate their Ethical Dimensions

- What are the short- and long-term options, given the assessment of the public health issue and context in Step I?

- What are the ethical dimensions and tensions of each option?

- Utility: Does the public health action produce the best balance of benefits over harms and other costs?

- Equity and Justice: Is health equity advanced? Are the benefits and burdens distributed fairly (distributive justice)? Is there appropriate public participation, including the participation of affected parties (procedural justice)?

- Respect for Individual and Community Interests: Does the public health action respect self-determination and human rights, as well as civic roles and community values (e.g., trustworthiness, solidarity) (Dawson and Jennings 2012)?

- Other Moral Considerations in Public Health: Are there other moral considerations in public health that are important to consider? (For example, reciprocity, solidarity, protecting privacy and confidentiality; keeping promises and commitments; or disclosing information and speaking honestly, sometimes grouped as transparency.)

Step III: Provide Justification for a Particular Public Health Decision

- Effectiveness: Is the public health action likely to be effective?

- Proportionality: Will the probable benefits of the action outweigh the infringed moral considerations?

- Necessity: Is the action necessary (i.e., will overriding a conflicting ethical norm achieve an important public health goal)?

- Least Infringement: Is the public health action the least restrictive means available?

- Public Justification: Can decision makers offer public justification in the political and cultural context that stakeholders, the public, and those most affected find acceptable?

Consider the following scenario described by Melnick (2015a). A family adopted several children from a developing country with a high tuberculosis (TB) prevalence, including multidrug-resistant TB (MDR-TB). Screening on arrival revealed that the children were infected with TB but did not have active disease and were not contagious. The family has strong religious beliefs about medical care and refused treatment, immunizations, and other preventive care. The children were home- 
schooled, but they did attend community activities. Soon after arrival one of the teenage children developed TB symptoms, and after several months the family consulted a pediatrician who diagnosed active pulmonary TB. Cultures revealed that the child had MDR-TB. Directly observed treatment (DOT) is part of the standard of care for active TB in the United States, and the local health department nurse visited the family to provide DOT. The parents objected to the home visit, stating that DOT was an invasion of their privacy and parental rights. The health department has the statutory authority to require in-person DOT and even impose isolation of the case and removal from the family to protect the public's health. What should health officials do? Drawing on questions in Step I, health officials might first clarify the harms and risks and the goals of public health action. The public health goals are to prevent TB transmission and ensure the child receives appropriate care. Requiring DOT creates risks for the child such as side effects from treatment and social and behavioral harms associated with isolation and loss of privacy during visits, and potential community harm, by driving cases underground. Who are the stakeholders, and what are their moral claims?

\footnotetext{
There are several stakeholders: the child, the child's family (including parents but also several siblings), and the public, which expects the health department to protect the community from TB. Regarding moral claims, the child has some expectations of freedom of movement, and privacy; the family has similar expectations regarding privacy, respect for parental rights, and the freedom to administer medications to their child at a convenient time and place. However, these claims are not absolute, and competing moral claims can outweigh them. The child has a moral claim that could compete with her parent's claim, specifically, that receiving DOT will reduce the risk of inappropriate treatment and relapse compared to having her parents administer the medications. In addition, the public has a moral claim based on two expectations: (1) that the health department will protect the community from $\mathrm{TB}$, and (2) that people contagious for TB and other infectious diseases will protect others by behaving in an appropriate manner, including staying home when contagious and cooperating with treatment recommendations. This is especially concerning in this case because the immigration health officials had discussed the risks with the parents, warning them to seek treatment as soon as the child developed symptoms, yet the parents waited several months before taking the child to a pediatrician (Melnick 2015a, 175).
}

Consider another short scenario that illustrates the value of exploring options under Step II. A new policy is being considered that would require parental consent for newborn screening. Parental consent currently is not required, although newborn testing is not conducted if there are parental objections. The health department has been asked to take a position on the pending policy. What position should the health department take? What are the options?

Options include mandatory screening without consent, routine screening with advance notification (Opt In), routine screening without advance notification (Opt Out) (i.e., screening and testing done unless the parents object), voluntary screening (i.e., screening requires full consent and might also include a pre- and post-counseling session with each new mother). Some arguments that might be offered against requiring parental consent focus on the fact that (1) the benefits of screening are obvious and substantial, relative to potential harms; (2) parents have few good reasons to justify parental refusal and place their child at risk for harm; (3) obtaining 
consent from each parent is difficult, costly, and an unwarranted expenditure of time and money; and (4) the history of newborn screening has become acceptable and routine. Some arguments that may be raised for requiring parental consent include (1) parental consent is necessary because refusal of newborn screening is reasonable given the increasing list of diseases included in the battery of newborn tests and the low probability of many of these diseases; (2) newborn screening can have adverse consequences such as psychological harms associated with false positive tests; (3) long-term parental caretaking is enhanced when parents are included in all clinical decisions about their children; and (4) the process of obtaining consent need not be time-consuming or burdensome but rather can help enhance the health professionalpatient relationship (CDC 2012). Which arguments are stronger, and which of the options are the most ethically justifiable? The answer may depend on the social and political context in which the issue is considered, and which ethical values carry weight in that context. Whether there were presumptive values in place would be explored through the questions in Step I, which examines previous cases, the applicable laws and policies, and stakeholder claims in context. So, for example, in a society that has a strong moral norm or presumption for solidarity, there could be a presumption for continuing population newborn screening without parental consent. On the other hand, for a society that has a liberal political context that has a presumption for individual liberty, there may be a presumption for an option that seeks more explicit consent from parents. In either context, the presumptive moral norms are not determinative but are rebuttable, so the arguments or reasons to override those norms must be stronger.

Consider a third case from public health practice in which a person (the index case) infected with primary syphilis and HIV refuses to provide contact information for his wife, insisting that he and his wife had not had sexual relations for several years. Contact tracing and partner notification have been important tools historically for public health officials, although these interventions can involve thorny ethical tensions, requiring health officials to justify their decisions. In this type of situation, health officers will consider several options, starting with those that infringe least on the index case's choices. For example, they might first provide to the index case additional information and assurance about confidentiality while allowing him to notify his wife voluntarily, either alone or with the help of public health workers. If this proves unsuccessful, other interventions might be considered, such as incentives, the threat of restrictions such as isolation, or attempts to notify the wife without his knowledge or consent. Each of these options would be determined in context, using the questions in Step III. Questions considered may include (1) Would the options likely accomplish the goal of warning and testing the wife without risking greater harm or possible adverse outcomes for the wife (e.g., domestic violence, loss of income, or loss of housing)? (2) Is there significant concern about a risk of harm to others, such as family members or children, so that the burdens and benefits of the action would not be distributed fairly? (3) Is the action the least restrictive of the important moral claims of the stakeholders? (4) Is it necessary now to override conflicting claims to achieve the public health goal? Answering the questions in Step III helps decision makers consider whether actions are justifiable. As one 
health officer explains, "Public health officials should justify their decisions with deliberations that build not only community support and trust, but also build support and trust from the individuals and families directly affected" (Melnick 2015b).

As the scenarios illustrate, public health is a social and political undertaking. Thus, making difficult choices in public health implicates important social, cultural, and political norms embedded in a particular context and community of stakeholders (Childress and Bernheim 2008). Regardless of whether decision makers work in a government public health agency, community nonprofit, nongovernmental organization (NGO) from another country, or a global organization, decision makers must rigorously assess the public health issue in context, to minimally be able to act "in ways that preserve the moral foundations of social collaboration" at the core of collective health activity (Calabresi and Bobbitt 1978).

The context specifically includes attention to stakeholders and relationships among public health stakeholders and community members, including the common understanding of their roles, obligations, and collaborations. Especially in global public health, it is important to note that even the decision makers are stakeholders, in some sense, and often, when they are health professionals, they have their own social-cultural norms and their own professional codes that can provide guidance. Appeals to the codes of particular professions, however, do not provide a sufficient justification for a public health decision, since justifications should be grounded in a society's widely shared ethical values and norms.

Engaging stakeholders and addressing claims, especially those of the people most affected by a public health issue, in ethical analysis, is especially important and can sometimes support and strengthen the collaboration and cohesion needed for public acceptance of a decision. The ways to engage and reason with stakeholders in an ethical analysis will vary in different settings and communities, depending on community values, cohesion, and expectations, and can range from establishing an ethics board for deliberation, to gathering information from focus groups or social media, to including stakeholder representatives on the decision-making team. Stakeholder norms and claims are a critical feature for an ethical analysis in order to achieve a primary goal in public health-the development and maintenance of relationships of trust, defined in a report from IOM as "the belief that those with whom one interacts will take one's interests into account, even in situations in which one is not in a position to recognize, evaluate, or thwart a potentially negative course of action by those trusted" (IOM 1996).

Ethical analysis is a dynamic process and, particularly for the practice of public health, is best accomplished through group deliberations that involve understanding others' perspectives and thinking independently and imaginatively. Public health professionals often have to decide how best to realize numerous important societal norms and values when pursuing public health goals. Ethical tensions do occur in public health and at times require overriding an important principle, value, or moral consideration to undertake a justifiable public health action. However, a structured ethical analysis can often lead to imaginative alternatives that transcend or minimize ethical tensions and to decisions that most or many stakeholders find acceptable. 
Open Access This chapter is distributed under the terms of the Creative Commons AttributionNoncommercial 2.5 License (http://creativecommons.org/licenses/by-nc/2.5/) which permits any noncommercial use, distribution, and reproduction in any medium, provided the original author(s) and source are credited.

The images or other third party material in this chapter are included in the work's Creative Commons license, unless indicated otherwise in the credit line; if such material is not included in the work's Creative Commons license and the respective action is not permitted by statutory regulation, users will need to obtain permission from the license holder to duplicate, adapt or reproduce the material.

\section{References}

ABIM Foundation, ACP-ASIM Foundation, and European Federation of Internal Medicine. 2002. Medical professionalism in the new millennium: A physician charter. Annals of Internal Medicine 136: 243-246.

Bartlett, R., and S. Collins. 2011. Aristotle's Nicomachean ethics. Chicago/London: University of Chicago Press.

Beauchamp, D.E. 1976. Public health as social justice. Inquiry 13(1): 3-14.

Beauchamp, T.L., and J.F. Childress. 2012. Principles of biomedical ethics, 7th ed. New York: Oxford University Press.

Bernheim, R.G., P. Nieburg, and R.J. Bonnie. 2007. Ethics and the practice of public health. In Law in public health practice, 2nd ed, ed. R.A. Goodman, 110-135. New York: Oxford University Press.

Blane, D. 1999. The life course, the social gradient, and health. Social Determinants of Health 2: 54-77.

Blas, E., L. Gilson, M.P. Kelly, et al. 2008. Addressing social determinants of health inequities: What can the state and civil society do? Lancet 372(9650): 1684-1689.

Braveman, P. 2006. Health disparities and health equity: Concepts and measurement. Annual Review of Public Health 27: 167-194.

Brunk, C.E., L. Haworth, and B. Lee. 1991. Value assumption in risk assessment: A case study of the alachlor controversy. Waterloo: Wilfrid Laurier University Press.

Calabresi, G., and P. Bobbitt. 1978. Tragic choices. New York: Norton.

Callahan, D., and B. Jennings. 2002. Ethics and public health: Forging a strong relationship. American Journal of Public Health 92(2): 169-176.

Centers for Disease Control and Prevention (CDC). 2011. Advancing excellence \& integrity of CDC science. Public health ethics. http://www.cdc.gov/od/science/integrity/phethics/. Accessed 14 Feb 2014.

Centers for Disease Control and Prevention. 2012. Unit 2: Ethics and the law. In Public Health Law 101: A foundational case for public health practices. Public Health Law Program, Centers for Disease Control and Prevention. http://www.cdc.gov/phlp/publications/phl_101.html. Accessed 24 June 2015.

Childress, J.F., and R.G. Bernheim. 2008. Public health ethics: Public justification and public trust. Bundesgesundheitsblatt, Gesundheitsforschung, Gesundheitsschutz 51(2): 158-163. doi:10.1007/s00103-008-0444-6.

Childress, J.R., R.R. Faden, R.D. Gaare, et al. 2002. Public health ethics: Mapping the terrain. Journal of Law, Medicine \& Ethics 30(2): 170-178.

Council for International Organizations of Medical Sciences (CIOMS). 2002. International ethical guidelines for biomedical research involving human subjects. Geneva: Council for International Organizations of Medical Sciences. http://www.cioms.ch/publications/layout_guide2002.pdf. Accessed 14 Feb 2014. 
Dawson, A. 2011. Resetting the parameters: Public health as the foundation for public health ethics. In Public health ethics: Key concepts and issues in policy and practice, ed. A. Dawson, 1-19. Cambridge: Cambridge University Press.

Dawson, A., and B. Jennings. 2012. The place of solidarity in public health ethics. Public Health Reviews 34: 65-79.

Dawson, A., and M. Verweij. 2007. The meaning of "public" in public health. In Ethics, prevention, and public health, ed. A. Dawson and M. Verweij, 13-29. Oxford: Clarendon Press.

Faden, R., and S., Shebaya. 2010. Public health ethics. In Stanford encyclopedia of philosophy, ed. E. N. Zalta. http://plato.stanford.edu/archives/sum2010/entries/publichealth-ethics/. Accessed $14 \mathrm{Feb} 2014$.

Freiler, A., C. Muntaner, K. Shankardass, et al. 2013. Glossary for the implementation of Health in All Policies (HiAP). Journal of Epidemiology and Community Health 67: 1068-1072. doi:10.1136/jech-2013-202731.

Gregor, M., J. Timmermann, and C.M. Korsgaard (eds.). 2012. Kant: Groundwork of the metaphysics of morals. New York: Cambridge University Press.

Hyder, A., M. Merritt, J. Ali, N. Tran, K. Subramaniam, and T. Akhtar. 2008. Integrating ethics, health policy and health systems in low- and middle-income countries: Case studies from Malaysia and Pakistan. Bulletin of the World Health Organization 86(8): 606-610.

Institute of Medicine (IOM). 1988. The future of public health. Washington, DC: National Academy Press.

Institute of Medicine. 1996. Healthy communities: New partnerships for the future of public health. Washington, DC: National Academy Press.

Jennings, B. 2007. Public health and civic republicanism. In Ethics, prevention, and public health, ed. A. Dawson and M. Verweij, 30-58. Oxford: Oxford University Press.

Kass, N. 2001. An ethics framework for public health. American Journal of Public Health 91(11): $1776-1782$.

Kickbusch, I. 2003. The contribution of the World Health Organization to a new public health and health promotion. American Journal of Public Health 93(3): 383-388.

Krimsky, S., and A. Plough. 1988. Environmental hazards: Communicating risks as a social process. Dover: Auburn House.

Lee, L.M. 2012. Public health ethics theory: Review and path to convergence. Journal of Law Medicine \& Ethics 40(1): 85-98.

Louw, D.J. 2008. The African concept of ubuntu and restorative justice. In Handbook of restorative justice: A global perspective, ed. D. Sullivan and L. Tifft, 161-171. New York: Routledge.

Marks, L., D.J. Hunter, and R. Alderslade. 2011. Strengthening public health capacity and services in Europe: A concept paper. Geneva: World Health Organization. http://www.euro.who.int/_ data/assets/pdf_file/0007/152683/e95877.pdf. Accessed 10 Dec 2013.

Marmot, M. 2007. Achieving health equity: From root causes to fair outcomes. Lancet 370: 1153-1163.

Melnick, A.L. 2015a. Chapter 8, Containing Communicable Diseases: Personal Control Measures. In Essentials of public health ethics, ed. R.G. Bernheim, J.F. Childress, R.J. Bonnie, and A.L. Melnick, Burlington: Jones \& Bartlett Learning.

Melnick, A.L. 2015b. Chapter 6, Case finding: Screening, testing, and contact tracing. In Essentials of public health ethics, ed. R.G. Bernheim, J.F. Childress, R.J. Bonnie, and A.L. Melnick, Burlington: Jones \& Bartlett Learning.

Michaels, D. 2008. Doubt is their product: How industry's assault on science threatens your health. New York: Oxford University Press.

Mill, J.S. 1989. In On liberty and other writings, ed. S. Collini. Cambridge: Cambridge University Press.

Nuremberg Code. 1947. Trials of war criminals before the Nuremberg Military Tribunals under Control Council Law No. 10, vol. 2, 181-182. Washington, DC: U.S. Government Printing Office, 1949. http://www.hhs.gov/ohrp/archive/nurcode.html. Accessed 3 June 2014.

O'Neill, O. 2002. Autonomy and trust in bioethics (Gifford lecture). Cambridge: Cambridge University Press. 
Ortmann, L., and J. Iskander. 2013. The role of public health ethics in vaccine decision making: Insights from the Centers for Disease Control and Prevention. In Vaccinophobia and vaccine controversies of the 21 st century, ed. A. Chatterjee, 291-305. New York: Springer.

Powers, M., and R. Faden. 2006. Social justice: The moral foundations of public health and health policy. New York: Oxford University Press.

Powers, M., R. Faden, and Y. Saghai. 2012. Liberty, mill and the framework of public health ethics. Public Health Ethics 5(1): 6-15.

Public Health Functions Steering Committee. 1994. Essential public health services. http://www. health.gov/phfunctions/public.htm. Accessed 2 Jan 2014.

Public Health Leadership Society. 2002. Principles of the ethical practice of public health. http:// phls.org/CMSuploads/Principles-of-the-Ethical-Practice-of-PH-Version-2.2-68496.pdf. Accessed 1 Feb 2013.

Riley, P. 1982. Will and political legitimacy: A critical exposition of social contract theory in Hobbes, Lock, Rousseau, Kant, and Hegel. Cambridge, MA: Harvard University Press.

Ruger, J. 2010. Health and social justice. New York: Oxford University Press.

Sen, A. 2009. The idea of justice. London: Allen Lane.

Singer, P.A., S.R. Benatar, M. Bernstein, et al. 2003. Ethics and SARS: Lessons from Toronto. British Medical Journal 327(7427): 1342-1344.

Sodeke, S. 2012. Tuskegee University experience challenges conventional wisdom: Is integrative bioethics practice the new ethics for the public's health? Journal of Health Care for the Poor and Underserved 23(4): 15-33. doi:10.1353/hpu.2012.0169.

U.S. Department of Health and Human Services. 2009. Code of Federal Regulations, Title 45, Part 46, Protection of Human Subjects. http://www.hhs.gov/ohrp/humansubjects/guidance/45cfr46. html. Accessed 3 June 2014.

U.S. Department of Health and Human Services. 2015. International Compilation of Human Research Standards. Office for Human Research Protections. http://www.hhs.gov/ohrp/international/intlcompilation/2015internationalcompilation.doc.doc. Accessed 23 June 2015.

U.S. Department of Health, Education, and Welfare. 1979. The Belmont report: Ethical principles and guidelines for the protection of human subjects of research, Publication No. (OS) 78-0012. Washington, DC: U.S. Government Printing Office.

Verweij, M., and A. Dawson. 2009. Public health ethics: A research agenda. Public Health Ethics 2(1): $1-6$.

Whitehead, M. 1992. The concepts and principles of equity and health. International Journal of Health Services 22(3): 429-445.

Winslow, C.-E.A. 1920. The untilled fields of public health. Science 51(1306): 23-33.

World Health Organization (WHO). 2006. Constitution of the World Health Organization-Basic documents, 45th ed., suppl. www.who.int/governance/eb/who_constitution_en.pdf. Accessed 29 Apr 2014.

World Health Organization (WHO). 2007. A conceptual framework for action on the social determinants of health (Discussion paper draft). Geneva: Commission on Social Determinants of Health, World Health Organization. http://www.who.int/social_determinants/resources/csdh_ framework_action_05_07.pdf. Accessed 4 Mar 2014.

World Health Organization (WHO). 2008. Closing the gap in a generation: Health equity through action on the social determinants of health, Final Report of the Commission on Social Determinants of Health. Geneva: Commission on Social Determinants of Health, World Health Organization. http://whqlibdoc.who.int/publications/2008/9789241563703_eng.pdf. Accessed 4 Mar 2014.

World Medical Association (WMA). 1964, 1975, 2013. WMA Declaration of Helsinki-Ethical principles for medical research involving human subjects. http://www.wma.net/ en/30publications/10policies/b3/. Accessed 4 Mar 2014. 